\title{
Targeting Perioperative Performance Aligned to Hospital Strategy via Digital Transformation
}

\author{
Jim Ryan \\ Worcester Polytechnic Institute \\ jryan@wpi.edu \\ Sandra Daily \\ University of Alabama-Birmingham Hospital \\ sldaily@uabmc.edu
}

\author{
Barbara Doster \\ University of Alabama-Birmingham Hospital \\ bdoster@uabmc.edu
}

\author{
Carmen Lewis \\ Troy University \\ cclewis@troy.edu
}

\begin{abstract}
This study examines the digital transformation of a U.S. hospital's perioperative process, which yields targeted performance alignment to strategy. Based on a 184-month longitudinal study of a large 1,157 registered-bed academic medical center, the observed effects are viewed through a lens of information technology (IT) impact on core capabilities and core strategy. The results offer a framework that supports patient-centric improvement and targets alignment of perioperative sub-process efforts to overall hospital strategy. This research identifies existing limitations, potential capabilities, and subsequent contextual understanding to minimize perioperative process complexity, target and measure improvement, and ultimately yield process management and hospital strategy alignment. Dynamic activities of analysis, evaluation, and synthesis applied to specific perioperative patient-centric data, collected within integrated hospital information systems, provide the organizational resource for management and control. Conclusions include theoretical and practical implications as well as study limitations.
\end{abstract}

\section{Introduction}

Ten years ago, the United States Congress passed the Health Information Technology for Economic and Clinical Health (HITECH) Act that authorized incentive payments, through the Centers for Medicare \& Medicaid Services (CMS), for U.S. clinicians and hospitals to adopt and use electronic health records (EHRs) [5]. The CMS EHR Incentive Program (CMSEHRIP) quickened the digital transformation of healthcare delivery across the U.S. healthcare ecosystem to exploit the consensus that health information technology (IT) value propositions will improve healthcare quality and reduce costs [2]. CMS incentives accelerated the adoption rate of EHR technology among U.S. hospitals - up from only $7.6 \%$ in 2008 [17]. Currently, over $95 \%$ of U.S. hospitals eligible for CMSEHRIP have achieved some level for meaningful use of certified EHRs [26]. Likewise, the widespread healthcare IS/IT adoption necessitates the need for realized value [16]. Hospital administration also must consider the strategic IS and business alignment challenges experienced in other industries over the past decades [20] as well as in healthcare [6].

In 2016, U.S. healthcare spending accounted for \$3.3 trillion dollars and approximately one-third of the cost was hospital care (i.e., \$1.08 trillion) [8]. Similarly, CMS estimates U.S. healthcare spending to exceed $\$ 4.3$ trillion in 2021 , so the healthcare IT value propositions sought via digital transformation are essential to address rising healthcare costs. In addition, the Joint Commission on Accreditation of Healthcare Organizations (TJC), and CMS require performance and clinical outcome reporting as evidence of organizational quality, efficiency, and effectiveness. To meet these demands, administrators and medical professionals alike must leverage healthcare IT [28]. However, successful digital transformation requires strategy on application and change management in addition to technology implementation [13]. Digital transformation of healthcare processes provide a foundation for more agile data collection, analysis, and process managementallowing new service opportunities and customer experiences within the healthcare environment [2]. To this end, this study examines digital transformation in a hospital environment and the resulting associated perioperative performance integrated into daily workflows and aligned to hospital strategy.

Within the hospital environment, patients and their care are the focus of work. Operationally, a hospital's perioperative process (i.e., workflow) provides surgical care for inpatients and outpatients during preoperative, intra-operative, and immediate post-operative stages. Perioperative surgical care requires teams of multidisciplinary professionals, synchronously or asynchronously, to maneuver within complex, fastpaced, and critical situations. The perioperative process reflects patient flow, safety, and quality of care as well as stakeholders' satisfaction (e.g., patient, physician, nurse, perioperative staff, and hospital administration). Financially, the perioperative process is typically the primary source of hospital admissions [27], with the largest percentage of variable hospital costs [21]. Consequently, digital transformation offers opportunities to redesign processes for quality improvement, efficiency, and cost effectiveness [2]. 
This research investigates complexity and change dynamics identified during a longitudinal study of an integrated clinical scheduling IS (CSIS) implementation, integration, and use. The systematic analysis and subsequent contextual understanding prescribed opportunity for measured improvement. Specifically, this study investigates the research question as to how digital transformation can assist in targeting perioperative performance aligned to hospital strategy.

The following sections review previous literature with respect to digital transformation, business process management (BPM), and key performance indicators (KPIs). Following the literature review, we present our methodology, case study background, observed effects, and discussion. By identifying a holistic system to align targeted perioperative workflow to hospital strategy, this paper prescribes an a priori context for the occurrence. The conclusion also addresses study contributions, limitations, and implications.

\section{Literature Review}

A digital business strategy identifies how an organization aligns IT to create a fusion between IT strategy and business strategy [4]. Likewise, the digital business strategy distinguishes how healthcare providers leverage healthcare IT capabilities and differentiates the success level of digital transformation. To this end, Applegate, McFarland, and Austin [3] noted how organizations can view their core capabilities and core strategy through an IT lens to delineate IT impacts. The resulting IT Impact Map, illustrated in Figure 1, depicts the four quadrants and modes an organization can exhibit by varying IT impact levels on core capabilities versus core strategy.

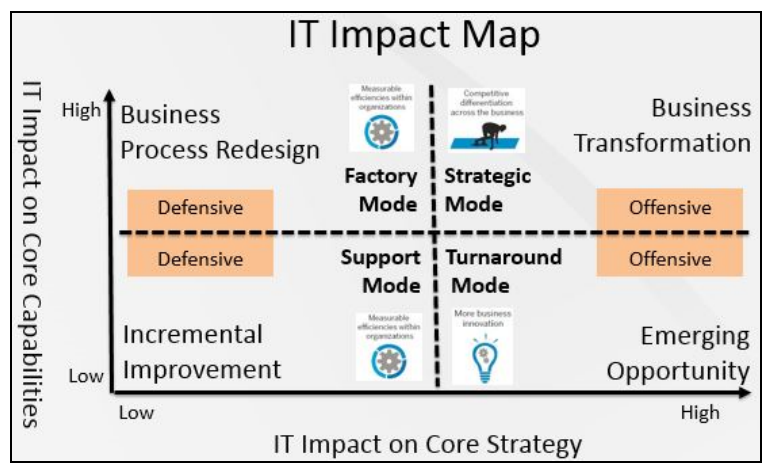

Figure 1 - IT Impact on Core Capabilities versus Core Strategy

With respect to Figure 1 in a hospital environment, the two modes with low IT impact on core strategy represent defensive healthcare IT applications (i.e., measurable efficiencies), which have the greatest impact internally within the hospital. The two modes with high IT impact on core strategy represent offensive healthcare IT applications (i.e., competitive differentiation), which have the greatest impact externally to the hospital. The following sections review literature on digital transformation, BPM, and KPIs as related to IT impact on core capabilities and core strategy.

\subsection{Digital Transformation}

Digital transformation is similar to the IT Impact Map's depiction of defensive and offensive IT impact. Digital transformation is evolutionary and leverages digital capabilities with emerging IT to create value by enabled business models, operational processes, and/or customer experiences [24]. Re-phrased, the changes new IT make via digital transformation impact the organization and result in changed business models, changed products or services, changed organizational structures, and/or the automation of business processes [13]. Moreover, the literature concurs that simply implementing or using IT is not enough to achieve digital transformation $[4,13,14,17,22,24,33,34]$. A key driver of digital transformation is the level of organizational digital maturity (e.g., higher is desired) found in the differences among organizational strategy, culture, and talent development [17]. Organizational culture, employee talent, as well as strategy all develop over time. Hence, digital transformation is evolutionary and organizations with higher digital maturity see more success through innovative IT implementation [17].

Forrester suggests digital transformation strategies focus on using IT to deliver internal operational excellence (i.e., defensive IT impact) and external customer experience (i.e., offensive IT impact) [34]. At the organizational level, digital transformation strategies have common dimensions where financial aspects must balance the use of IT, changes in value creation, and structural changes [22]. Digital transformation strategies also have cross-functional characteristics, which requires functional and operational strategy alignment or complex coordination efforts [22]. As an example of cross-functional characteristics at the patient level, the clinical use of IS and IT integration in acute critical care settings impacts patient monitoring, bedside charting, as well as coordination and management of artificial support devices.

\subsection{Business Process Management (BPM)}

This study uses the BPM definition provided by Jeston and Nelis [15, p. 10] as "the achievement of an organization's objectives through the improvement, management, and control of essential business processes." The authors further elaborate that process management and analysis is integral to BPM, where there is no finish line for improvement. Hence, this study views BPM as an organizational commitment to consistent and iterative process performance improvement that meets organizational objectives. As $\mathrm{BPM}$ requires alignment to strategic objectives, a BSC approach [19] embraces the ability to quantify 
organizational control metrics aligned with strategy across perspectives of: (1) financial; (2) customer; (3) process; and (4) learning/growth. Therefore, BPM success through BSCs has a strong dependence on contextual understanding of end-to-end core business processes [15]. Depicted in Figure 1, defensive IT identifies incremental improvement and business process redesign quadrants. Both low IT impacts on core strategy (e.g., incremental improvement and BPR) are internal to the organizaton and align within BPM.

Incremental improvement gains occur via iterative cycles of analysis, evaluation, and synthesis (i.e., plando-study-act) [38] to minimize observed variation. Incremental improvement as continuous process improvement (CPI) is a systematic approach to understanding process capability, customers' needs, and sources of variation. Tenner \& DeToro [35] views CPI as an organizational response to an acute crisis, a chronic problem, or an internal driver. CPI encourages bottom-up communication in day-to-day operations (i.e., patient level) and requires process data comparisons to control metrics. Doubt can exist as to whether: incremental improvement addresses symptoms versus causes; the improvement effort is sustainable; or management is in control of the process [15]. With respect to the IT Impact Map, IT capabilities within the incremental improvement quadrant are invisible to external stakeholders.

IT capabilities in the business process redesign (BPR) quadrant do not digitally replicate manual processes. BPR offers radical redesign when compared to CPI, with greater reward of upwards to 1,000 percent, while assuming higher risk, durations, costs, and difficulty [35]. BPR achieves dramatic improvements in performance (e.g. cost, quality, service, and speed) by questioning activity relevance and reinventing new ways to accomplish work. IT capabilities focused via BPR have core business processes online in real-time, yet the IT impact provides little strategic differentiation.

Business analytics within BPM focus on the effective use of organizational data and information to drive positive business action [33]. The effective use of business analytics demands knowledge and skills from subject matter experts and knowledge workers. Similarly, Wears and Berg [40] concur that IS/IT only yield high-quality healthcare when use patterns are tailored to knowledge workers and their environment. Business analytics offer technology solutions that incorporate definition and delivery of business metrics, performance dashboard management, data visualization, and data mining [37]. With respect to the IT Impact Map, BPM is applicable to either defensive or offensive healthcare IT applications.

\subsection{Perioperative KPIs}

Performance measurement is essential for purposeful BPM, as information before and after the intervention is an integral part of process improvement.
Early in the IT literature, Ackoff [1] proposed embedding control feedback in IS design to avoid management misinformation. Similarly, organizations define data metrics as KPIs to monitor critical success factors (CSFs) [25] within business processes (i.e., organizational action). The perioperative process is information intensive [7], due to its complexity [10].

Operational and tactical KPIs in perioperative subprocesses are numerous, but intra-operative KPIs should include: (1) monitoring the percentage of surgical cases that start on-time (OTS) or first-of-the-day surgical case on-time starts (FCOTS), (2) OR turn-around time (TAT) between cases, (3) OR utilization (UTIL), and (4) labor hours expended per patient care hour as units-of-service (UOS), [41, 12, 18, 27]. Customer experience KPIs should include Consumer Assessment of Healthcare Providers and Systems surveys for patient perspectives of hospital care (i.e., HCAHPS) or clinician group care (i.e., CGCAPHS) [11], as well as employee satisfaction surveys. Tarantino [36] noted how OR TAT and a flexible work environment are CSFs for physician satisfaction, which in turn is a CSF for hospital margin. Poor KPIs on operational and tactical metrics (e.g., OTS, TAT, UTIL, UOS, or HCAHPS) affect strategic CSFs of patient safety, patient quality of care, surgeon/staff/patient satisfaction, and hospital margin $[11,23,27]$. With respect to the IT Impact Map, KPIs are applicable to measure performance in either defensive or offensive healthcare IT applications.

\section{Research Method}

This research investigates the digital transformation of a hospital's perioperative process and questions the framework as to how digital transformation can assist in targeting perioperative performance aligned to hospital strategy. To this end, case research is particularly appropriate [9, 42]. An advantage of the positivist approach [39] to case research allows concentrating on a specific hospital service in a natural setting to analyze the associated qualitative problems and environmental complexity. Hence, our study took an in-depth case research approach.

Our research site (i.e., University Hospital) is an academic medical center, licensed for 1,157 beds and located in the southeastern region of the United States. University Hospital is a Level 1 Trauma Center, with a robotics program over eight surgical service specialties (SSS) as well as a Women's/Infant facility. University Hospital's recognition includes Magnet since 2002 and a Top 100 Hospital by U.S. News and World Report since 2005. Concentrating on one research site facilitated the research investigation and allowed collection of longitudinal data. This research spans activities from August 2003 through December 2018, with particular historical data since 1993. During the 184-month study, we conducted field research and collected data via multiple sources including interviews, 
field surveys, site observations, field notes, archival records, and document reviews.

\section{Case Study Background}

Perioperative Services (UHPS) is the University Hospital department designated to coordinate and manage perioperative patient care across Preadmissions, Admissions, Surgical Preparations (PreOP), Central Sterile Supply (CSS), Intra-operative and Endoscopy (OR), and Post Anesthesia Care Units (PACU). The workflow through CSS reprocesses all reusable surgical instruments/devices and transports supplies to and from PreOP, OR, and PACU areas.

UHPS replaced its prior CSIS of 10 years in 2003. The new CSIS supports OLAP tools, a proprietary structured query language, and both operational and managerial data stores (i.e., an operational database and separate data mart). Flexible routing templates as surgical preference cards (SPCs) allow standardization of surgical care data (i.e., particular supplies and instruments) or SPC customization for specific surgeons and/or procedures. Since the new CSIS implementation, over 7,750 generic and custom SPC configurations facilitate the surgical specialty services (SSS) represented in Table-1. Similarly, the CSIS data mart serves as the central repository for perioperative process data used to support improvement initiatives as well as report KPIs via a business intelligence layer for data visualization. The following sections highlight tools, events, and outcomes that have shaped UHPS' BPM approach.

Table-1 - University Hospital SSS

\begin{tabular}{|l|r|}
\hline Surgical Service Specialty (SSS) & SPCs \\
\hline BURN - Trauma burns & $\mathbf{2 6}$ \\
CARDIO - Cardiovascular \& Thoracic & $\mathbf{9 4 6}$ \\
ENT - Ear, Nose, \& Throat & $\mathbf{1 , 0 3 0}$ \\
GI - Gastro-intestinal & $\mathbf{4 6 0}$ \\
GYN - Obstetrics, oncology, incontinence & $\mathbf{6 1 1}$ \\
NEURO - Neurological & $\mathbf{7 6 3}$ \\
ORAL - Oral Maxil Facial & $\mathbf{2 3 6}$ \\
ORTHO - Orthopedic, joint/device & $\mathbf{1 , 2 0 8}$ \\
PLAS - Plastic surgery & $\mathbf{6 8 1}$ \\
SURG ONC - Surgical oncology & $\mathbf{3 2 9}$ \\
TX - Transplants (liver, renal) & $\mathbf{1 9 4}$ \\
TRAUMA - Trauma, MASH & $\mathbf{2 0 3}$ \\
URO - Urology & $\mathbf{5 3 3}$ \\
VASCULAR - arteries \& blood vessels & $\mathbf{5 5 8}$ \\
\hline
\end{tabular}

\subsection{Perioperative Process Improvement}

University Hospital opened a new diagnostic and surgical facility (i.e., North Pavilion) in November 2004. The new facility expanded UHPS' OR capacity by $33 \%$, providing state-of-the-art OR suites having standardized as well as surgical specific equipment.
Within six weeks of occupancy, a scheduling KPI reflected chaos. Surgical OTS plunged to $18 \%$ during December 2004. Having only $18 \%$ OTS is unacceptable, as $82 \%$ of scheduled surgeries experience delays and risk patient care and safety.

In January 2005, UHPS expressed concerns before a quickly convened meeting of c-level, nursing, and physician representatives. The meeting yielded a hybrid matrix-style management structure and governance in the formation of a multidisciplinary executive team, empowered to evoke change. The executive team consisted of perioperative stakeholders (e.g., surgeons, anesthesiologists, nurses, and UHPS), chartered to focus on patient care and safety, attack difficult questions, and remove inefficiencies. The resulting CPI effort addressed the perioperative crisis via numerous task forces employing data-driven evaluation of specific opportunities, which founded UHPS' current BPM approach [29]. Table 2 details a complete listing and timeline of UHPS' perioperative improvements.

Table 2 - Perioperative Improvements

\begin{tabular}{|c|lc|}
\hline $\begin{array}{c}\text { Sub- } \\
\text { process }\end{array}$ & \multicolumn{1}{|c}{ Improvement } & Yr. \\
\hline All & Implemented the current CSIS & 2003 \\
All & Relocated CSS and ORs & 2004 \\
$\underline{\text { All }}$ & Governance change--initiated CPI & $\underline{\mathbf{2 0 0 5}}$ \\
OR & Initiated OR heuristic scheduling & 2006 \\
& Hospital-wide patient flow (EMR, & 2007 \\
All & patient tracking, CPoE, etc.) & \\
All & Established KPI reporting (strategic, & 2008 \\
& tactical, and operational) & \\
All & AMC21 Balanced Scorecards & 2010 \\
PreOP & Developed PACT Clinic & 2011 \\
OR & RFID phased implementation & 2012 \\
CSS \& & Redesigned supply workflow & 2013 \\
OR & (CSS-to-OR-to-CSS) & \\
All & Unit-of-service charges via EMRs & 2014 \\
CSS \& & Instrument reprocessing \& tracking & 2015 \\
OR & (CSS-to-OR-to-CSS) & 2016 \\
All & Real-time perioperative dashboards & 2017 \\
All & Automated EMR Reconciliation & \\
\hline
\end{tabular}

Since 2005, UHPS has expanded its management beyond the initial general (GENOR) and cardio-vascular (CVOR) ORs of the North Pavilion campus. UHPS management includes other campuses of the University Hospital Health System (UHHS) including OR suites at the Highland campus (HHOR) and Endoscopy (ENDO) labs at the TK Clinic campus. UHPS also developed a preoperative assessment, consultation, and treatment (PACT) clinic to manage all PreOP patient flow into UHPS. The PACT Clinic exists virtually in the CSIS, so the TK Clinic and HHOR allocated physical space for patient evaluations. Overall, UHHS has experienced a $10.9 \%$ increase in surgical cases since 2007 with 59\% 
of the average case volume being in-patient and $41 \%$ being out-patient. Emergency surgeries account for $5.3 \%$ of the average case volume. Surgical case volume during FY2018 was 44,287 cases over the 58 ORs and 11 endoscopy labs.

UHPS focuses BPM on data-driven analysis of KPIs at strategic, tactical, and operational levels via balanced scorecards and dashboards, aligned to hospital strategy [31]. To this end, numerous BPM efforts have targeted multiple perioperative sub-processes to improve patient workflow [30]. All BPM efforts in Table 2 leveraged specific defensive healthcare IT applications (i.e., Figure 1) to improve perioperative capabilities, with examples being: OR scheduling; hospital-wide electronic medical record (EMRs) integration; preoperative patient evaluations; radiofrequency identification; and CSS/OR supply workflow.

\subsection{Patient flow and integrated hospital IS}

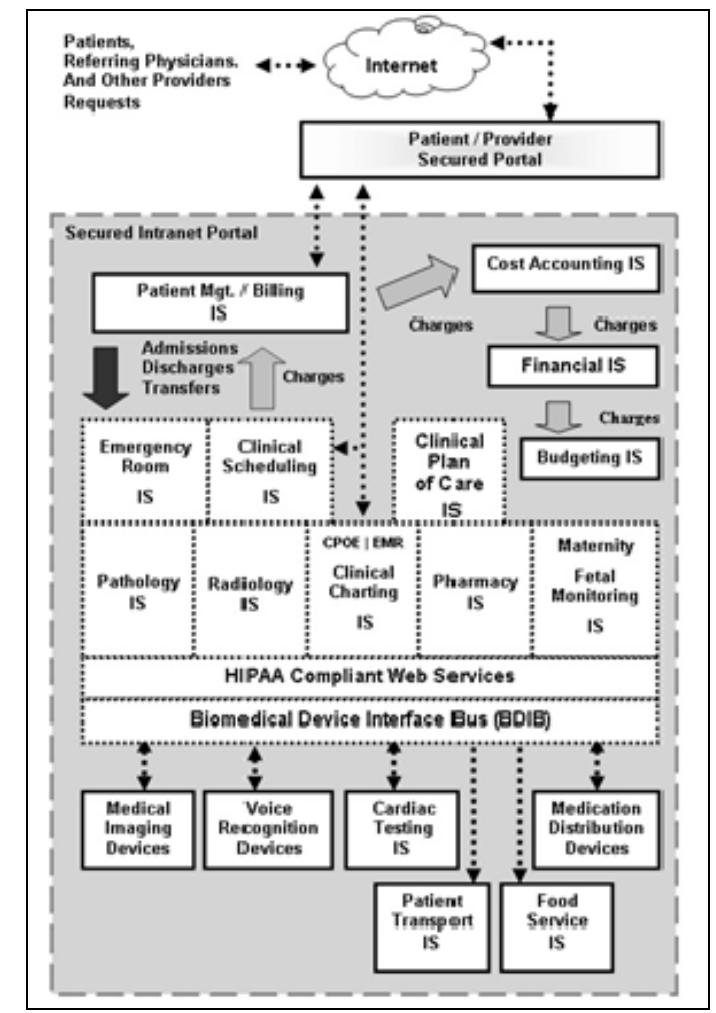

Figure-2 UHHS Integrated IS

Surgical patient admissions occur via the PACT Clinic, with referrals via three venues: 1) diagnostic office visits to physicians within the TK Clinic, 2) nonUHHS physicians, or 3) the Emergency Department. All surgical patients receive a PACT Clinic evaluation prior to their scheduled procedures. Figure- 2 depicts the integrated hospital IS used to facilitate and document perioperative patient care across UHHS. UHHS patients' (i.e., in-patient or outpatient) medical records, admissions, diagnostics, clinical data and observations, as well as discharges are processed and recorded via the same integrated hospital IS. All IS depicted in Figure-2 are integrated with either uni-directional constraints for limited data exchange or bi-directional data exchange. The seven IS clustered around the CSIS are modules that directly support and extend the CSIS suite, where the Clinical Charting IS houses CPoE and EMRs. The HIPPA compliant Web services and BMDIB (i.e., biomedical device interface bus) integrate ancillary IS, clinical data sensors, and bio-medical equipment. The institutional intranet serves as single entry portal access to extend each IS according to particular user-IS rights and privileges negotiated via user authentication.

\section{Perioperative Observed Effects}

Surgical patients move through the perioperative workflow via events: (1) A clinic visit resulting in scheduling a patient's surgery, (2) PACT Clinic evaluation, (3) day of surgery Admissions, (4) PreOP, (5) Intra-operative or Endoscopy, (6) PACU, (7) PACU Phase-II, and (8) discharge or movement to a medical bed. As noted in Table 2, the digital transformation of UHPS' patient care and documentation within the workflow occurs via corresponding CSIS EMRs and is facilitated via the integrated hospital IS depicted in Figure 2 [32]. Within two weeks of hospital discharge or a UHHS clinic visit, patients receive satisfaction surveys (HCAHPS or CGCAHPS) to provide feedback on their UHHS patient experience. The patient satisfaction data is collected, analyzed, and aggregated as a KPI metric. The patient/provider portal (e.g., depicted in Figure 2) also supports patient experience via communication with healthcare providers, health record information, upcoming appointments, or medication renewal requests.

Using KPIs and other core UHHS process metrics to monitor perioperative performance has been an iterative evolution since 2005. A consistent focus has been on data-driven, end-to-end improvement, with performance measures collected through the CSIS and benchmarked to external industry standards or prior months' metrics. Digital transformation and the BPM approach pushed UHPS to achieve operational excellence as evidenced by the initiatives in Table 2 . When reviewing what could have been done better during the initial 2005 CPI efforts, UHPS recognized the need to involve stakeholders across improvement efforts and not just end-result to-do lists. Consequently, the executive team launched an initiative in 2008 for perioperative performance feedback as well as meeting CMS and TJC regulatory requirements. The BPM effort established BSC KPIs (e.g. process, customer, and financial) and a means to disseminate the process feedback to stakeholders at strategic, tactical, and operational levels. The BPM approach was expanded in FY2010 to reinforce UHHS strategy across all core hospital processes. After an introduction to the overall 
UHHS strategy that drives the BPM approach, the following sections detail the digitally transformed strategic alignment via targeted workflow occurs.

\subsection{UHHS Strategy-AMC21}

As noted in Table 2, the BPM initiative implemented in 2010 was labeled AMC21. AMC21 is UHHS's strategy to reaffirm core healthcare quality standards from CMS and TJC, while complimenting core hospital process measures. Strategically, AMC21 positions UHHS' mission to be, "The preferred academic medical center of the 21 st century," through its vision "To be preferred" and its goals to: 1) deliver outstanding patient care; 2) develop advancements in scientific discovery and biomedical research; and 3) provide a strong foundation of education and training for professionals.
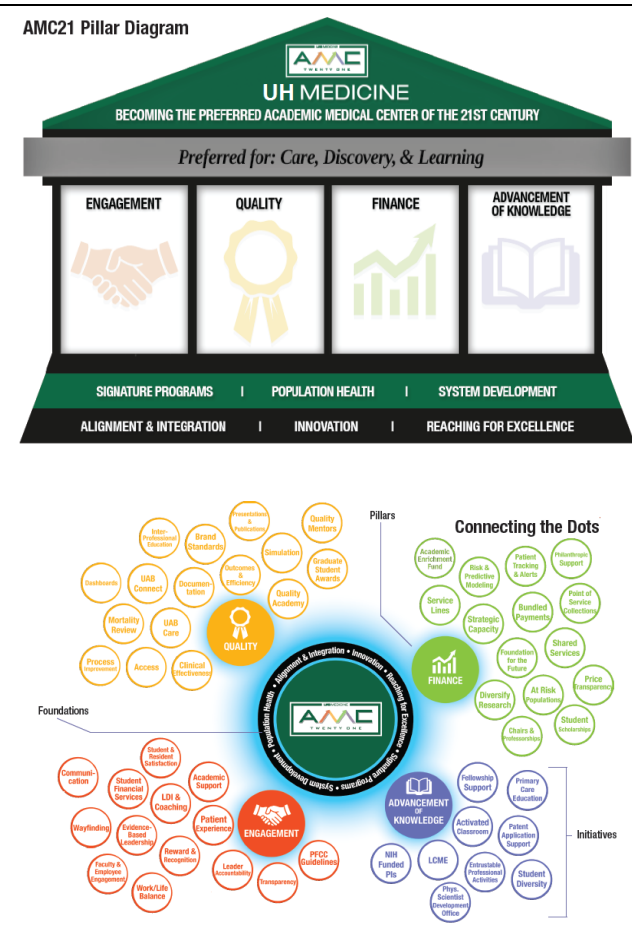

Figure 3 - AMC21 Pillar Diagram | Connecting the Dots Initiatives

Supporting the AMC21 mission and vision are BSC pillars or perspectives to view goal accomplishment. The four AMC21 pillars map to the four perspectives of the BSC [19] approach: 1) customer (i.e., engagement); 2) process (i.e., quality); 3) financial (i.e., finance); and 4) learning/growth (i.e., knowledge advancement). UHHS updated AMC21 in 2017 to address healthcare changes since 2010 by adding three new foundational components to address Signature Programs, Population Health, and System Development.

The bedrock for AMC21 mission, vision, and goals, supported by BSC pillar perspectives and grounded by foundational components, is alignment and integration to encourage collaboration, communication, and organizational effectiveness; innovation to harvest new ideas, fresh approaches and scientific breakthroughs; as well as reaching for excellence to align goals, measure outcomes, and create a system of accountability within workflows.

Figure 3 depicts the AMC21 pillar diagram, as well as the tactical initiatives necessary for connecting the dots to achieve the vision and mission of UHHS. The AMC21 pillar diagram illustrates UHHS strategy. Connecting the dots are tactical UHHS initiatives necessary for AMC21 strategy execution. The reach for excellence (i.e., RFE) layer is the keystone of the pillar diagram that provides the digital transformation capability of targeted operational performance aligned to AMC21 mission, vision, and goals. With respect to Figure 1 (i.e., IT Impact Map), the RFE layer directs defensive and offensive IT capability via BPM.

\subsection{AMC21-Reach For Excellence Layer}

To align departmental and stakeholder efforts with AMC21 strategy, UHHS administration implemented an intranet-based goal setting and reporting tool to leverage existing process data via integrated IS and provide an extended business intelligence application layer. The "Reach for Excellence" (RFE) layer provides process management review capabilities for qualitative or quantitative measures across UHHS that are measurable and aligned through AMC21 pillars to support AMC21 goals and vision. The purpose for the RFE layer is to provide an objective tool to measure process and stakeholder performance toward tactical and operational efforts to support AMC21 strategy.

RFE goals are designed to measure objective outcomes. Rather than classify tactics, projects, or activities, RFE goals are aggressive and realistic, where fewer is better. RFE goals change focus as AMC21 progress advances. Consequently, each year UHHS administration reviews opportunities for improvement and identifies the most important RFE outcomes needed. Many RFE goal measures do not change each year as they are important outcomes for success. However, the iterative nature of the goal setting process yields more aggressive targets for those familiar goals. Hence, administrators set RFE goals so stakeholders focus on specific efforts and the targeted RFE outcomes align to AMC21 strategy via stakeholder action-a very powerful process management tool.

Figures 4 and 5 identify RFE goals, associated measures, and targets for AMC21 pillars engagement and quality, respectively. Likewise, Figures 6 and 7 illustrate the RFE goals, associated measures, and targets for AMC21 pillars finance and knowledge advancement, respectively. Targeted perioperative performance and stakeholder action across BSC pillars aligns operational workflows to UHHS strategy. 


\begin{tabular}{|c|c|}
\hline \multicolumn{2}{|l|}{ Engagement } \\
\hline \multicolumn{2}{|c|}{$\begin{array}{l}\text { Develop and strengthen satisfying relationships between UAB } \\
\text { Medicine and its patients, facuity, staff, and students. }\end{array}$} \\
\hline MEASURE & TARGET \\
\hline $\begin{array}{l}\text { nctrease patent satisfaction as measured by } \\
\text { HCAMPS }\end{array}$ & ToD $10 \%$ of HCAHPS \\
\hline $\begin{array}{l}\text { nctease patent satisfaction as measured by } \\
\text { UPCAMPS }\end{array}$ & ToO $10 \%$ of MPCANPS \\
\hline $\begin{array}{l}\text { ncrease employee engagement as measured } \\
\text { py Press Ganey }\end{array}$ & Top 10\% \\
\hline Top 100 Places to Work & $\begin{array}{l}\text { Modern Heathcare relative } \\
\text { ranking }\end{array}$ \\
\hline $\begin{array}{l}\text { ncrease American Association of } \\
\text { Medical Colleges Graduation Ouessonnaire } \\
\text { fatistaction score }\end{array}$ & $\begin{array}{l}\text { 50th percentile of US medical } \\
\text { schoots }\end{array}$ \\
\hline $\begin{array}{l}\text { ncrease } \$ \text { of tesidents and bio- } \\
\text { fedical graduate students indicating UAB } \\
\text { vas "prefecred training program" }\end{array}$ & $\begin{array}{l}\text { Internal survey (set baseine and } \\
\text { \% improvement) }\end{array}$ \\
\hline $\begin{array}{l}\text { ncrease facuity engagement as measured by } \\
\text { JHC }\end{array}$ & $\begin{array}{l}\text { 75th percentile for facuify and } \\
\text { both percentile for physician } \\
\text { paculty in UHC }\end{array}$ \\
\hline
\end{tabular}

Figure 4 - RFE Goal | Engagement (i.e., Customer)

\begin{tabular}{|c|c|}
\hline Quality & 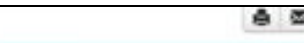 \\
\hline \multicolumn{2}{|c|}{$\begin{array}{l}\text { Implement standards and systems to continue achieving } \\
\text { the best possible results in clinical care, resesrch, and } \\
\text { education. }\end{array}$} \\
\hline MEASURE & TARGET \\
\hline $\begin{array}{l}\text { mprove cinical eflectivecess as measured } \\
\text { py UHC }\end{array}$ & Top 10 \% of UHC \\
\hline $\begin{array}{l}\text { nocresse complance with evidence-based } \\
\text { puidoines as detioes by UH Care }\end{array}$ & $\begin{array}{l}100 \% \text { complance if guibelinet ave } \\
\text { approgrises }\end{array}$ \\
\hline pecrease montaily as measured by UHC & To0 105 \\
\hline horease publication score & 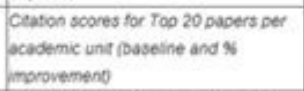 \\
\hline nocrease number of training grants & TEO (Daspline and $\$$ improverment \\
\hline 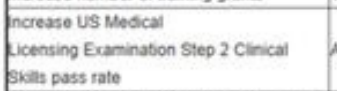 & No $\alpha$ above the natonal poss rase \\
\hline $\begin{array}{l}\text { ncciesie specially boovd exam pass rates } \\
\text { oo at residency programs }\end{array}$ & $\begin{array}{l}100 \% \text { of propraess above national } \\
\text { mean }\end{array}$ \\
\hline
\end{tabular}

Figure 5 - RFE Goal | Quality (i.e., Process)

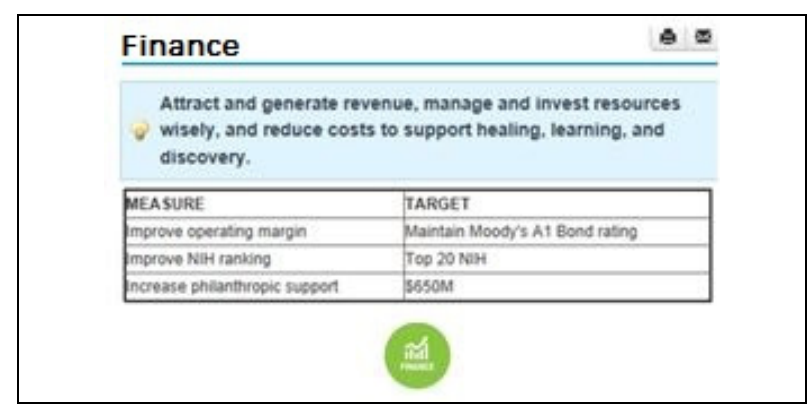

Figure 6 - RFE Goal | Finance (i.e., Financial)

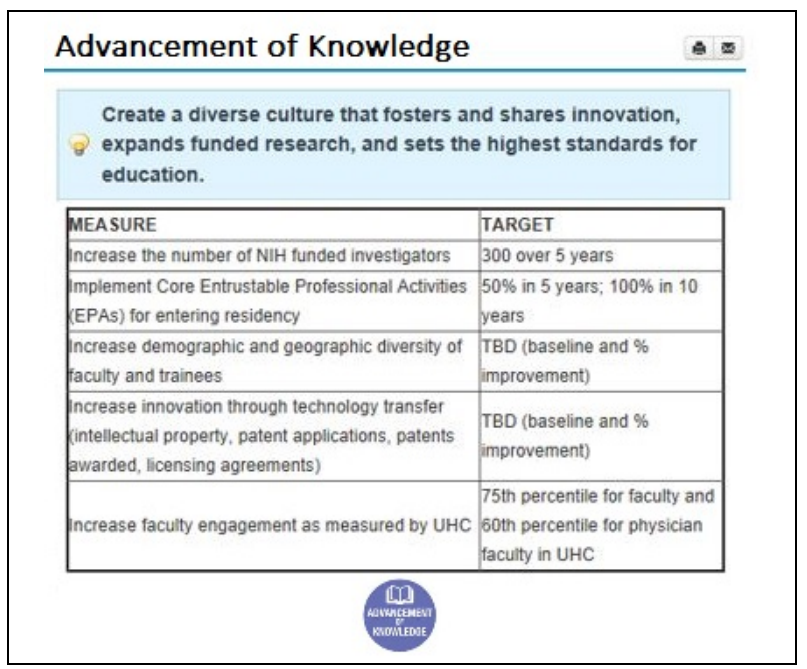

Figure 7 - RFE Goal | Knowledge (i.e., Learning)

\subsection{Targeted Workflow Aligned to Strategy}

Department and individual employee effort contribute toward achieving AMC21 RFE goals. RFE goal attainment and performance measurement is a formal, digitally transformed activity integrated into UHHS departmental resource budgeting as well as individual employee evaluation and performance reviews. AMC21 RFE goals coordinate and target department and individual employee workflow. As a result, many perioperative KPIs measure and resulting CPI/BPR efforts support RFE goals. As such, UHPS stakeholders focus on achieving RFE process outcomes through AMC21 pillars and advancing connect the dots initiatives to yield aligned stakeholder action. Combined, all hospital departments and process stakeholders (e.g. physicians, surgeons, nurses, staff, and administrators) have action plans that align to AMC21 RFE goals and map through pillars and initiatives to execute AMC21 strategy. The RFE layer provides objective BPM with varied incentive levels to target workflow performance aligned to strategy.

UHHS departmental budget funding is a function of how well the department meets RFE goals. Likewise, employee merit increases and bonuses are linked to individual employee's RFE goal attainment. Figure 8 depicts a RFE performance dashboard for a single SSS department (e.g., refer to Table 1) during early Q4. This SSS departmental budget has $\$ 235,196$ set to be earned (i.e., At-Risk) via RFE target achievement. As of lateJuly, all of the department's engagement $(\$ 35,029)$ and quality $(\$ 47,039)$ targets were met, as well as $66.5 \%$ of the finance $(\$ 85,994)$ and $25 \%$ of the knowledge $(\$ 5,880)$ targets. The remaining $25.9 \%(\$ 60,824)$ of the total RFE targeted workflow performance payout was at risk unless specific RFE finance ( $\$ 43,364$ or 33.5\%) and knowledge $(\$ 17,640$ or $75 \%)$ targets are met later during Q4. Drilling down into any of the four AMC21 pillars on Figure 8 will yield the corresponding RFE 
goal measures that comprise the SSS department's potential budget earnings. As an example of the drilldown capability, Figure 9 reflects all the Engagement RFE goal measures that represents the $\$ 35,029$ budget earning awarded to the specific SSS department. Notice how each measure in Figure 9 has multiple targets associated with different funding levels to provide higher incentives to reward higher performance against a given measure.

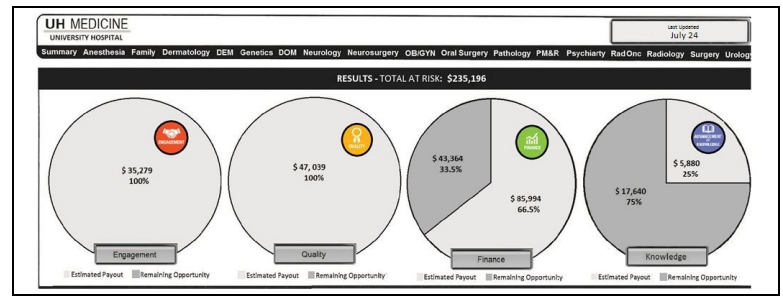

Figure 8 - SSS Q4 RFE Performance Dashboard

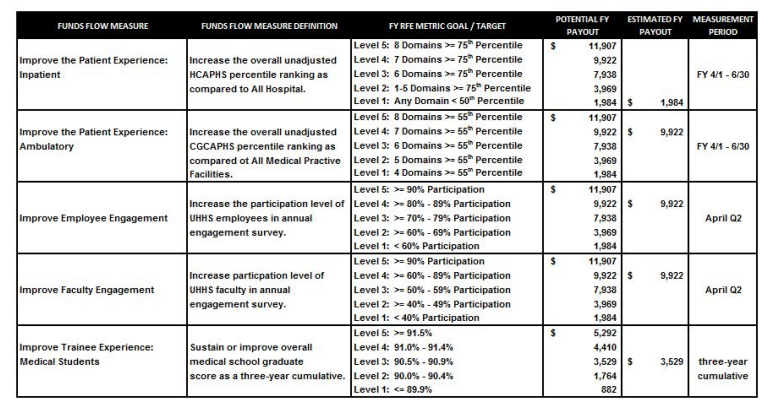

Figure 9 - SSS Engagement RFE Goal Measures

\section{Discussion}

The previous sections on case background and observed effects illustrate the digital transformation of UHHS' perioperative process where UHPS' BPM and CSIS integration efforts support a tight coupling between patient care, perioperative workflow (i.e., patient flow), and integrated hospital IS. The CSIS and integrated hospital IS yield aggregated surgical case (i.e., patient) data as KPI metrics to understand, manage, and improve perioperative workflow. Consequently, the AMC21 RFE layer directs and incentivizes department and individual efforts to target outcomes across varied performance levels. The following sub-sections discuss a BPM framework, digital maturity, defensive to offensive IT impact, as well as CSFs with respect to the literature, case background, and observed effects.

\subsection{BPM Framework}

The strategic, tactical, and operational execution of AMC21 strategy has digitally evolved since FY2010. Figure 10 depicts how UHHS positions BPM techniques to align processes to strategy. UHHS developed its AMC21 mission, vision, and core goals external to the BPM framework, but used BPM principles in its update. Hospital processes flow across UHHS and provide the workflow channels where clinical outcomes occur. Clinical outcomes and preceding stakeholder actions are recorded and collected by the integrated CSIS and other UHHS IS as process data. The digital transformation of BPM techniques at the RFE layer allow goal setting with measures and incentivized targets to maintain or improve results, monitor and measure stakeholder action, and target workflow aligned to strategy.

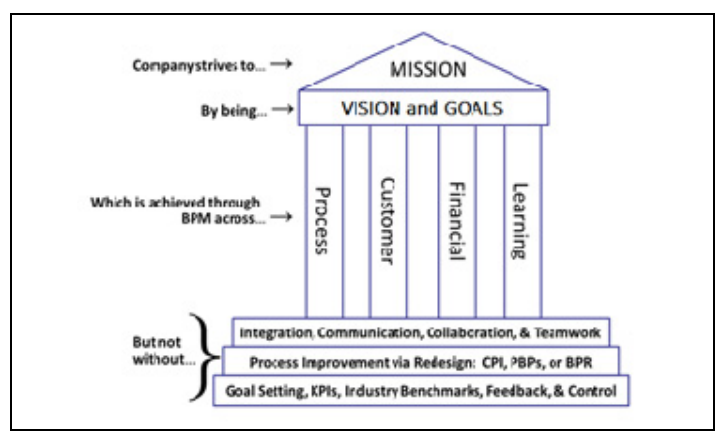

Figure 10 - Observed BPM Framework

The BPM framework requires sufficient identification of goals, measures, and incentives in order to focus departmental and individual stakeholder action. Using this systematic and multi-level BPM approach, process improvement interventions (e.g., Table 2) can also occur within particular lower-performing processes to target specific improvements as identified bottom-up and/or topdown by process stakeholders (e.g., subject matter experts, knowledge workers, and/or administration). The observed BPM framework yields targeted performance aligned to strategy.

\subsection{Digital maturity}

Strategy, culture, and employee talent reflect the level of organizational digital maturity - a CSF for digital transformation [17]. With respect to strategy, digital transformation requires reconfiguring business processes to exploit IT impact and information through integrated digital technologies (i.e., AMC21 - RFE layer). Increasing IT impact on capabilities with low IT impact on strategy (e.g., Figure 1) moves a hospital in incremental improvement to business process redesign. UHPS uses CSIS data in CPI and BPR via business analytics, OLAP, and data mining (e.g., see Table 2). Likewise, high IT impact on strategy and increasing IT impact on capabilities moves a hospital from emerging opportunity to business transformation. Table 2 is evidence of UHPS implementing healthcare IT innovatively. The aggregated CSIS data and customer satisfaction surveys yield KPIs for performance measurement. The RFE layer aligns workflow to AMC21 strategy and allows emerging opportunities to transform UHHS.

Organizational culture can leverage IT for digital transformation. Examples, already explained in the case background and observed effects sections, are UHPS' BPM approach and UHHS' AMC21 RFE layer that 
leveraged IT to impact core process capabilities and core strategy execution, respectively.

Personnel who understand the business and IT impact on processes is necessary to leverage IT for digital transformation [17]. UHHS administration understand that leveraging IT requires perioperative subject matter experts with IT and analytical skills. With respect to operational and tactical efforts, UHPS has consistently taken perioperative registered nurses (RNs) and trained them in healthcare IT support as nursing educators, CSIS analysts, OR schedulers, CSS supervisors, or robotics nurses. Strategically, the RFE layer incentivizes departmental and individual employee workflow alignment.

\subsection{Defensive to offensive IT impact}

The BPM efforts applied to the perioperative process positioned UHHS to achieve operational excellence (i.e., defensive IT), as evidenced by the Table 2 improvement efforts and increased workflow reflected in OTS KPI metrics. Figure 11 depicts OTS KPIs since FY2005.

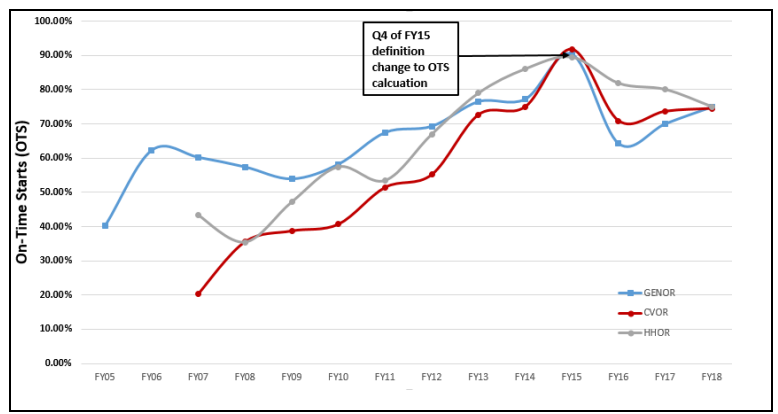

Figure 11 - OTS between FY2005 and FY 2008

In turn, operational excellence positioned UHHS to capitalize on patient experiences via perioperative event occurrences as well as enhanced collaboration between healthcare providers and patients. Patient experience surveys and the patient/provider portal are examples of leveraging healthcare IT to further extend the external customer experience (i.e., offensive IT) by respectively providing communication, feedback, and providerpatient care collaboration opportunities. Figure 12 depicts weekly HCAPHS survey results in percentiles via the RFE layer as patient experience feedback.

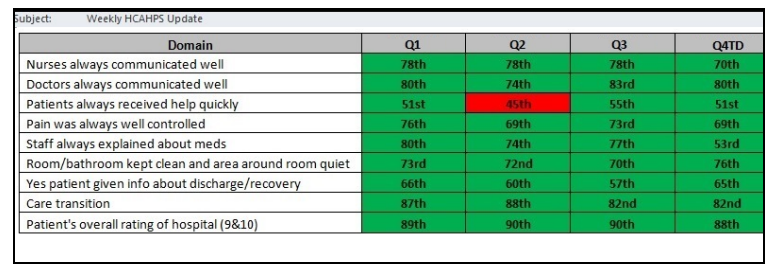

Figure 12 - HCAPHS Surveys Percentiles Q1-Q4

\subsection{UHHS BPM Framework CSFs}

Digital transformation offers productivity, process performance management, and meeting customer experience expectations [14]. Likewise, BPM efforts since FY2005 digitally transformed processes. AMC21 execution also yields productivity, data-driven improvement, and patient-centric performance. The following CSFs support the BPM framework that aligns stakeholder action to strategy via digital transformation:

The integrated CSIS as an operational backbone with the HIPPA compliant Web services and BMDIB as a digital services platform.

$\square$ Accessible and visible data via the CSIS having high data quality and data integrity.

$\square$ Changed governance using matrix-style management from cross-functional departments.

$\square$ An organizational culture focused on continuous improvement using data-driven decision-making.

$\square$ Empowered multi-disciplinary teams as IT literate knowledge workers and subject matter experts.

\section{Conclusion}

Empowered individuals, integrated IS, digitally transformed processes, and a holistic BPM framework allows UHHS administration to direct strategic, tactical, and operational performance aligned to strategy. The BPM framework via the RFE goals, RFE layer measures and targets, and performance incentive dashboards provide departmental and employee performance feedback and focus targeted through BSC perspectives. Departmental and employee targeted actions align with the overall hospital strategy.

This study has limitations. Generalization to other hospitals would be conditional as to whether the hospital's IS architecture is equipped with a digital services platform required to facilitate implementation and integration of digital innovation opportunities. The study also is limited to a single case, where future research should broaden focus as well as address other limitations inadvertently overlooked.

Overall, the study results were exploratory and need further confirmation. The case examples can serve as momentum for perioperative methodology, complexity comprehension, and improvement extension. Researchers may choose to further or expand the investigation, while practitioners may apply the practices and BPM framework within their perioperative environment.

\section{References}

[1] Ackoff, R. (1967). "Management misinformation systems," Management Science, 14(4), 142-156.

[2] Agarwal, R., et al. (2010). "Research Commentary-The Digital Transformation of Healthcare: Current Status and the Road Ahead," ISR, 21(4), 796-809.

[3] Applegate, L., McFarlan, F. \& Austin, R., (2009). Corporate Information Strategy and Management: Text and Cases. 8th ed. New York: Irwin/McGraw-Hill. 
[4] Bharadway, A., et al., (2013). "Digital Business Strategy: Toward a Next Generation," MIS Quarterly, 37(2), 421-482.

[5] Blumenthal, D. \& Tavenner, M., (2010). "The 'Meaningful Use' Regulation for EHRs," NEJoM, 363(6), 501-504.

[6] Bush, M., et al, (2009). "The alignment of information systems with organizational objectives and strategies in health care," IJoMI, 78(7), 446-456.

[7] Catalano, K. \& Fickenscher, K. (2007). "Emerging technologies in the OR and their effect on perioperative professionals," AORN Journal, 86(6), 958 - 969.

[8] CMS. "National Health Expenditures data." Available https://www.cms.gov/Research-Statistics-Data-and-Systems/St atistics-Trends-and-Reports/NationalHealthExpendData/Nat ionalHealthAccountsProjected.html. Accessed June 9, 2019.

[9] Eisenhardt, K., (1989). "Building theories from case study research", Academy of Mgt. Review, 14(4), 532-550.

[10] Fowler, P., et al., (2008). "Perioperative workflow: barriers to efficiency," AORN Journal, 87(1), 187-208.

[11] HCAHPS, (2017). "HCAHPS Fact Sheet." Available https://www.hcahpsonline.org/globalassets/hcahps/facts/hcahp s_fact_sheet_november_2017.pdf. Accessed June 13, 2019.

[12] Herzer, K. et al., (2008). "Designing and implementing a comprehensive quality and patient safety management model," Journal of Patient Safety, 4(2), 84 - 92.

[13] Hess, T., et al.., (2016). "Options for formulating a digital transformation strategy," MISQE, 15(2), 123-139.

[14] IDG (2018). "State of digital business transformation." Available via https://www.idgconnect.com/abstract/30222/idgresearch-the-digital-business-transformation-landscape. Accessed 6/9/2019.

[15] Jeston, J. \& Nelis, J. (2008). Business Process Mgt: Practical Guidelines to Successful Implementations, 2nd ed. Burlington, MA: Elsevier, Ltd.

[16] Jones S., et al. (2014). "Health IT: An updated systematic review with a focus on meaningful use," AoIM, 160(1), 48-54

[17] Kane, G., Palmer, D., Phillips, A., \& Kiron, D., (2015). "Is your business ready for a digital future?," MIT Sloan Management Review, 56(4), 37-44.

[18] Kanich, D. \& Byrd, J., (1996). "How to increase efficiency in the operating room," Surgical Clinics of North America, 76(1), 161 - 173.

[19] Kaplan, R. \& Norton, D., (1996). The Balanced Scorecard. Boston: Harvard Business School Press.

[20] Kappelman, L., et al., (2017). “The 2017 SIM IT issues and trends study," MIS Quarterly Executive, 17(1), 53 - 86.

[21] Macario, A., et al. (1995). "Analysis of hospital costs and charges for inpatient surgical care," Anesthesiology, (83)6, $1138-1144$.

[22] Matt, C., Hess, T., \& Benlian, A., (2015). "Digital transformation strategies," Bus Inf Syst Eng, 57(5), 339-343.

[23] Marjamaa, R., Vakkuri, A., \& Kirvela, O., (2008). "Operating room management: why, how and by whom?," Acta Anaesthesiol Scandanavia, 52(5), 596-600.

[24] Morakanyane, R., Grace, A., \& O’Reilly, P., (2017). "Conceptualizing digital transformation in business organizations," BLED 2017 Proceedings, 21.
[25] Munroe, M., \& Wheeler, B., (1980). "Planning, critical success factors, and management's information requirements," MIS Quarterly, 4(4), 27 - 37.

[26] ONC (2017). "Hospital progress to meaningful use," available online 08/01/2017 via dashboard.healthit.gov/ quickstats/pages/FIG-Hospital-Progress-to-Meaningful-Useby-size-practice-setting-area-type.php. Accessed 6/9/2019.

[27] Peters, J. \& Blasco, T. (2004). "Enhancing hospital performance through perioperative services," Physician Executive, 30(6), 26 - 31.

[28] PwC (2012). "The future of the academic medical center," PricewaterhouseCoopers LLP, via http://www.pwc. $\mathrm{com} / \mathrm{us} / \mathrm{en} /$ health-industries/publications/the-future-ofacademic-medical-centers.jhtml\#, accessed 5/25/2019.

[29] Ryan, J., Doster, B., Daily, S., \& Heslin, M., (2008). "Soft Innovation as Data-Driven Process Improvement Exploited via Integrated Hospital Information Systems," Proceedings of the 41st Hawaii International Conference on System Sciences, Computer Society Press, 10.

[30] Ryan, J., Doster, B., Daily, S., \& Lewis, C., (2016). "A case study perspective for balanced perioperative workflow achievement through data-driven process improvement," IJHISI (11:3), 19-41.

[31] Ryan, J., Doster, B., Daily, S., \& Lewis, C., (2017). "Using key performance indicators to reduce perceived complexity \& improve patient workflow," IJHSI (12:4), 13-30.

[32] Ryan, J., Doster, B., Daily, S., \& Lewis, C., (2019). "A Case Study Perspective to the Digital Transformation of a Hospital's Perioperative Process," Proceedings of the 52nd Hawaii International Conference on System Sciences, http://hdl.handle.net/10125/59842, 10.

[33] Sebastian, I., et al., (2017). "How big old companies navigate digital transformation," MISQE, 16(3), 197-213.

[34] Schadler, T., \& Fenwick, N., (2017). "The digital business imperative," Forrester, available online 2/15/2017 via https://www.forrester.com/report/The+Digital+Business+Impe rative/-/E-RES115784, accessed June 9, 2018.

[35] Tenner, A.R., \& DeToro, I.J., (1997). Process redesign: the implementation guide for managers. Upper Saddle River, NJ: Prentice-Hall, Inc.

[36] Tarantino, D., (2003). "Process Redesign Part 1: Process Selection," The Physician Executive, 29(6), 71-73.

[37] Turban, E.; Sharda, R.; Aronson, J.; \& King, D. (2008). Business Intelligence: A managerial approach. Upper Saddle River, New Jersey: Prentice Hall

[38] Walton, M., (1986). The Deming Management Method. New York: Dodd, Mead.

[39] Weber, R., (2004). "The rhetoric of positivism versus interpretivism: a personal view," MIS Quarterly, 28(1): iii-xii.

[40] Wears, R. \& Berg, M., (2005). "Computer technology and clinical work: still waiting for Godot", JAMA, 293(10), 1261-1263.

[41] Wright, J., et al.,, (2010). "Improving on-time surgical starts in an operating room," CJoS, 53(3), 167-170.

[42] Yin, R. K., (2003). Case study research: Design and methods, Third Edition. Thousand Oaks, California: Sage. 